\title{
PENGARUH REPUTASI SEBAGAI VARIABEL INTERVENING TERHADAP KINERJA PERUSAHAAN PADA PT.TELKOM KEBUMEN
}

\author{
Sri Wahyuningsih, SE.,M.Si \\ Politeknik Dharma Patria Kebumen \\ yuni delpipo@yahoo.co.id
}

\begin{abstract}
The purpose of this study is to investigate the influence of social responsibility, etiuka relatives, on the reputation of corporate governance and its impact on the performance of the company PT. Telkom Indonesia Branch Kebumen. The analytical tool used Structural Equation Modeling (SEM).

The results of this study show that the reputation of social responsibility affects the reputation accepted. This is indicated by the value of $\mathrm{CR}=2.514$ and $\mathrm{p}=0.012$ or significant at $1 / 2 \alpha=0.05 \mathrm{t}$ table $= \pm 1.980$. Thus, the social responsibility variables formed by indicators of ethical codes, economic well-being, contributions and participant experiences have a significant influence on reputation. Further business ethics affects the accepted reputation. This is indicated by the value of $\mathrm{CR}=2.872$ and $\mathrm{p}=0.004$ or significant at $1 / 2 \alpha=0.05 \mathrm{t}$ table $= \pm 1.980$. Thus the business ethics variables formed by the indicators: Product quality, product trials, respect for human dignity, cultural integrity of the customer has an influence on reputation. Corporate governance affects acceptable reputation. This is indicated by the value of $\mathrm{CR}=3.241$ and $\mathrm{p}=0.001$ or significant at $1 / 2 \alpha=0.05 \mathrm{t}$ table $= \pm 1.980$. thus corporate governance variables formed by the indicators: Company competence, openness and transparency, policy implementation, corporate policy, confidence in top management, knowledge and ability of human resources. Reputation, effect on company performance accepted. This is indicated by the value of $\mathrm{CR}=13.933$ and $p=0,000$ or significant at $1 / 2 \alpha=$ $0.05 \mathrm{t}$ table $= \pm 1.980$. Thus the reputation variable formed by the Company's Vision indicators, the product offered, the emotional closeness of the customer to the company, the company's financial capability and confidence in the employee.

The limitations of this study on the structural model used, this model has been well seen from the test of cofirmatory and goodness-of-fit. but it is better for the company's performance topics to dig deeper into the variables and indicators used. Future research may also consider research objects that will be used not only in telecommunication service companies but can be developed in other business organizations.
\end{abstract}

\section{Key word: Reputation and Corporate Performance}

\section{Pendahuluan}

\section{Latarbelakang}

Perilaku Perusahaan tergantung dari bagaimana manager mengelola perusahaan (corporate governance) dan karateristik (social responsibilities) yang akan membentuk opini publik dan menjadi reputasi perusahaan yang kemudian berdampak pada kinerja (Thomas, 2006). Jika kita lihat pendapat Larkin dalam Suta (2006), menyatakan bahwa reputasi perusahaan adalah persepsi terhadap karateristik, perilaku perusahaan, dan kinerja, maka dapat di kontruksikan faktor-faktor pembentuk reputasi yang bersumber dari persepsi tersebut. Berikut akan disajikan beberapa penelitian yang menjadi Research Gap dalam penelitian ini :

Research Gap 1: Ekuitas Merek,

\section{Reputasi dan Kinerja}

Dalam beberapa studi empiris telah ditunjukan pentingnya hubungan antara 
ekuitas merek dan reputasi dalam mendorong kinerja perusahaan dilakukan oleh (Priem dan Butler, 2001a;. Rust et al. , 2004; Nguyen dan Leblanc, 2001; AragonCorrea dan Sharma, 2003 ; McMillan dan Joshi, 1997 dalam Wang et al (2006). Namun beberapa peneliti mempunyai pendapat berbeda seperti (Aaker, 1991; Karat et al, 2000 dalam Wang et al. 2006) yang mengasumsikan secara implisit bahwa ekuitas merek selalu mengarah pada kinerja CRM (customer relationship management) namun ada faktor antesenden untuk bergantung pada efek positif dari ekuitas merek terhadap kinerja CRM, dan kecenderungan sesuai dengan mengabaikan kemungkinan bahwa kepemilikan ekuitas merek mungkin memang lebih efisien, bahkan mungkin memiliki efek buruk pada kinerja bisnis dalam hal biaya yang terkait dengan mempertahankan ekuitas merek. Pendapat tersebut didukung oleh peneliti lainya yang disebutkan dalam Wang et al. (2006) yang menguji kontribusi reputasi perusahaan untuk beberapa aspek bisnis, dan ditemukan kecenderungan yang kuat untuk melihat ekuitas merek secara terpisah atau secara bergantian dengan mengabaikan interaksi potensial antara reputasi dan ekuitas merek.

Hasil temuan dalam penelitian Wang et al. (2006) ekuitas merek merupakan pendorong positif kinerja CRM dalam konteks model SEM (Structural Equation Modelling) dikembangkan dalam studi pelanggan perusahaan pialang di Cina. Selain itu dalam studi tersebut dinyatakan reputasi perusahaan memainkan kedua peran mediasi dan peran moderator dalam hubungan antara ekuitas merek dan menghormati kinerja. Ekuitas merek disebutkan mewakili suatu variabel penting yang secara signifikan berpengaruh terhadap kinerja CRM, langsung maupun tidak langsung.

Research Gap 2: Tanggung Jawab Sosial (Corporate Social Responsibility) dan Kinerja Keuangan

Menjalankan usaha dengan cara yang memenuhi atau melebihi harapan etika, hukum, komersial dan publik bahwa masyarakat memiliki "usaha" (Bisnis untuk Tanggung Jawab Sosial, www.bsr.org). Definisi ini tampaknya selaras dengan konsep Tripel P (People, Planet dan Profit), yang dianut dalam bisnis sebagai dasar CSR. Meskipun perbedaan antara kegiatan sosial dan ekonomi telah diterapkan di beberapa penelitian Maignan (2001), perbedaan antara keduanya adalah tipis. Aguilera et al. (2007) berpendapat, tujuan utama perusahaan adalah untuk bertahan hidup dengan cara mencapai keunggulan kompetitif di pasar ekonomi. Mekanisme CSR ada untuk mempertahankan kelangsungan hidup perusahaan dan efisiensi. Oleh karena itu, kegiatan CSR terkait dengan kinerja organisasi (yaitu kegiatan yang menghasilkan dari misi perusahaan dan bertujuan mencari keuntungan).

Perbedaan hasil penelitian oleh Gabriel et al (2009) yang menyatakan bahwa CSR tidak berpengaruh terhadap kinerja keuangan, dengan menggunakan 5 katagori utama dalam isu-isu CSR yaitu kualitas produk dan jasa, bisnis global, inovasi, budaya perusahaan, dan kewajiban etika. Namun demikian kontribusi pertama penelitian ini adalah untuk menciptakan kesadaran akan relevansi kekaguman dan hasil organisasi ketika membahas pengelolaan CSR. Bagi perusahaan menerapkan tindakan CSR, penggunaan kekaguman akan membantu stakeholder untuk memvisualisasikan skenario alternatif untuk tindakan di mana mereka memasukkan CSR ke dalam kegiatan mereka (Knez-Riedl et al, 2006.). Jumlah atau intensitas dari inisiatif CSR pada suatu saat memiliki dampak pada variabel organisasi (misalnya dalam hal kepercayaan investor meningkat, loyalitas pelanggan, konservasi bahan atau energi, pencegahan dampak negatif terhadap lingkungan, kepatuhan terhadap kode industri atau legislatif persyaratan, penurunan biaya, proses dan inovasi produk, antara lain), yang pada gilirannya berdampak pada kekaguman. Singkatnya, penggunaan kekaguman bisa memungkinkan para stakeholder untuk mengembangkan konsensus dan kreatif proses yang berkaitan 
dengan desain persyaratan baru di mana kegiatan CSR yang dimasukkan ke dalam kegiatan bisnis.

Uraian diatas menunjukan bahwa CSR dalam menciptakan aspek kinerja masih menjadi perdebatan para peniliti, oleh karena itu studi ini berupaya untuk memperoleh kejelasan hubungan antara CSR dengan Kinerja serta implikasinya.

\section{Research Gap 3: Kinerja Social}

\section{Perusahaan dan Reputasi Perusahaan}

Penelitian tentang kinerja social perusahaan (corporate social performance) pada reputasi perusahaan (corporate reputation) telah berkembang secara parallel dengan konsep teori perluasan untuk memasukan hubungan dengan stakeholder. Dalam beberapa kasus empiris dari kedua perseptif dengan menggunakan variabel yang sama, data dan metode mencapai hasil yang fundamental dan identik meskipun terdapat interprestasi yang berbeda. Dalam Penelitian Puente et al. (2007) menjelaskan perbedaan link dari penelitian yang dilakukan sebelumnya perbedaan utama tersebut adalah reputasi sebagai persepsi sedangkan konsep CSP adalah tindakan perusahaan dan sikap. Kalau melihat dari pendapat Friedman $(1962,1970)$ ia berpendapat bahwa tanggungjawab social perusahaan untuk memaksimumkan keuntungan sementara dengan menghormati aturan-aturan dasar yang ada di dalam masyarakat yang tercermin dalam hukum dan etika.

\section{Rumusan Masalah}

Dari uraian di atas peneliti merumuskan pertanyaan-pertanyaan penelitian sebagai berikut:
1) Apakah tanggungjawab social perusahaan berpengaruh terhadap reputasi perusahaan
2) Apakah etika bisnis berpengaruh terhadap reputasi perusahaan
3) Apakah tata kelola perusahaan berpengaruh terhadap reputasi perusahaan
4) Apakah reputasi perusahaan berpengaruh positif terhadap kinerja perusahaan.

\section{Tujuan Penelitian}

1) Menganalisis pengaruh tanggungjawab social perusahaan terhadap reputasi perusahaan

2) Menganalisis pengaruh etika bisnis terhadap reputasi perusahaan

3) Menganalisis pengaruh tata kelola perusahaan terhadap reputasi perusahaan

4) Menganalisis pengaruh reputasi perusahaan berpengaruh terhadap kinerja perusahaan

\section{A. Landasan Pustaka}

1) Kinerja Perusahaan

Penilaian kinerja pada dasarnya meruapakan faktor kunci untuk mengembangkan suatu organisasi secara efektif dan efisien, karena adanya kebijakan atau program yang lebih baik atas sumberdaya yang ada dalam perusahaan. Dimensi kinerja diukur dengan menggunakan ukuran kinerja yang dipakai oleh perusahaan.

Kriteria untuk kinerja bervariasi dan relevan sesuai dengan tujuan pengukuran, Murphy dan Cleaveland (1995) menyarankan agar dalam pemilihan kriteria ditentukan berdasarkan tujuan sistem, dan tujuan sistem diturunkan dari tujuan perusahaan dalam pengukuran kinerja perusahaan tersebut.

\section{2) Etika Bisnis (Businnes Ethics)}

Penelitian yang dilakukan Mouro et al. (1999) dalam Ernawan (2007) tentang etika bisnis dan pengambilan keputusan perusahaan menggunakan definisi etika dan etika bisnis yang dikembangkan oleh Walton. Menurut Walton (1977 dalam Mauro, 1999): Ethics. A critical analysis of human acts to determine their rightness or wrongness in terms of two major; truth and justice Business ethics. A range of criteria where by human actions are judge to include such things as societal expectations: fair competition ; the aesthetics or advertising and the used public relations; the meaning of social responsibilities; reconciling corporate behavior at home with behavior abroad; the extent of consumer sovereignty; the 
relevance of corporate size; the handling communications, and the like.

Maksudnya, etika merupakan analisis kritis tentang tindakan manusia untuk menentukan kebenaranya atau kesalahanya dalam kerangka 2 kriteria utama: kebenaran dan keadilan. Sementara etika bisnis merupakan sekumpulan kriteria di mana tindakan manusia di nilai berdasarkan harapan masyarakat. Hasil penelitian Mauro (1999) menemukan etika personal dan etika bisnis merupakan kesatuan yang tidak terpisahkan dan keberadaanya saling melengkapi dalam mempengaruhi perilaku manager. Banyak literatur yang mendukung pernyataan dan hasil penelitian ini. Bagi manager yang tidak mempunyai etika dalam bisnis adalah mereka yang hanya tergiur dengan keuntungan jangka pendek. Manager yang menjadikan keuntungan sebagai satusatunya tujuan bisa menyebabkan perusahaan menghalalkan segala cara untuk mengejar keuntungannya. Akibatnya merekapun sering mengabaikan nilai-nilai etika bisnis. Bisnispun dijalankan secara tidak jujur, tidak adil, melanggar kewajaran, penuh mark-up.

\section{3) Tata kelola Perusahaan (Corporate Governance)}

Tujuan utama dari tata kelola perusahaan adalah melindungi hak dan kepentingan pemegang saham, melindungi hak dan kepentingan para anggot stakeholder non pemegang saham, meningkatkan nilai perusahaan dan pemegang saham, meningkatkan efisien dan efektifitas kerja dewan pengurus dan manajemen perusahaan, meningkatkan mutu hubungan dewan pengurus dengan manajemen senior perusahaan. Tata kelola perusahaan mencakup hubungan antara para pemangku kepentingan (stakeholder) yang terlibat serta tujuan pengelolaan perusahaan. Pihak-pihak utama dalam tata kelola perusahaan adalah stakeholder, manajemen, dan dewan direksi. Pemangku kepentingan lainnya termasuk karyawan, pemasok, pelanggan, bank dan kreditor lain, regulator, lingkungan, serta masyarakat luas (Sutojo dan Aldridge, 2005).

\section{4) Reputasi}

Fombrun (1996) mendefinisikan reputasi perusahaan sebagai kombinasi dari kenyataan (kinerja sosial dan ekonomi) dan persepsi (kinerja yang dianggap penting oleh stakeholder). Fomburn juga menjelaskan bahwa reputasi perusahaan merupakan representasi persepsi dari tindakan perusahaan di masa lalu dan prospek di masa mendatang yang menggambarkan secara keseluruhan keingginan dari konstituennya (stakeholder) dibandingkan dengan pesaing. Stakeholder mengembangkan harapan bagaimana perusahaan akan bertindak dalam berbagai kondisi, gagal dalam memenuhi harapan itu maka akan memberikan reputasi yang buruk (Vandelo dalam Dolphin, 2004).

Sejalan dengan itu menurut Wartick (2002), reputasi perusahaan adalah persepsi masing-masing stakeholder secara agregat mengenai seberapa baik respon organisasional. Reputasi sangat penting bagi perusahaan karena di mata pelanggan dan masyarakat luas, dimana reputasi memberi gambaran terhadap kinerja perusahaan secara keseluruhan. Herbig et al. (1994) menjelaskan bahwa reputasi perusahaan dapat dilihat dari kompetensi perusahaan tersebut dan keunggulanya dibanding perusahaan pesaing. Pentingnya menjaga reputasi perusahaan yang positif, mewakili kinerja perusahaan dan dari sisi sosialnya, telah menjadi tujuan dari para eksekutif perusahaan dan jajaran direksi selama dekade terakhir. Tidak mengenali arti pentingnya reputasi maka akan menjadi kesalahan terburuk yang dilakukan oleh suatu ( Kartilia dalam Dolphin,2004). 


\section{Metode Analisis}

1) Definisi Konsep dan Opersional Variabel

Tabel 1. Definisi konseptual dan opersional variabel penelitian

\begin{tabular}{lll}
\hline Definisi Konseptual & Definisi Operasional & Indikator \\
Variabel & Variabel &
\end{tabular}

Tanggung Jawab Sosial adalah komitmen yang berkesinambungan dalam dunia bisnis untuk bertindak etis dan berkontribusi terhadap perkembangan ekonomi sementara meningkatkan kualitas hidup di tempat kerja dan keluarga pada khususnya, dan komunitas lokal dan sosial pada umumnya (Versi, 2007) Etika Bisnis adalah merupakan sekumpulan criteria di mana tindakan manusia di nilai berdasarkan harapan masyarakat (Maora,1999)

Tata Kelola Perusahaan adalah Sistem yang digunakan untuk mengarahkan dan mengelola kegiatan perusahaan ( Australian Stock Exchange)

Reputasi adalah serangkaian atribut yang melekat pada perusahaan yang berasal dari tindakan yang dilakukan perusahaan pada masa lalu (Weigelt dan Camerer, 2006)

Kinerja Perusahaan adalah pelaksanaan fungsi-fungsi yang di tuntut dari seseorang,merupakan suatu perbuatan, prestasi, pameran ketrampilan (John Whitmore, 1997)

Merupakan suatu
bentuk kebijakan
perusahaan yang
diwujudkan dengan
penerapan kode etis,
kepedulian terhadap
kesejahteraan ekonomi
lingkungan, kontribusi
program, bantuan dan
pengalaman
masyarakat.

Berkaitan dengan produk/jasa yang di tawarkan oleh perusahaan yang antara lain di ukur dari: mutu produk, uji coba produk, penghormatan terhadap martabat manusia, integritas budaya pelanggan Berkaitan dengan kemampuan perusahaan dalam hal: kompetensi perusahaan, keterbukaan dan tranparansi, implementasi kebijakan, kebijakan perusahaan, keyakinan pelanggan terhadap manajemen, pengetahuan dan skill SDM.

Berkaitan dengan visi perusahaan, produk yang ditawarkan, kedekatan emosional pelanggan, keyakinan pada karyawan

Berkaitan dengan penyelesaian terhadap keluhan, tingkat pelayanan serta kinerja jaringan.

\author{
Kode Etis \\ Kesejateraan Ekonomi \\ Kontribusi \\ Pengalaman peserta
}

Produk bermutu

Uji coba produk

Menghormati Martabat

Manusia

Integritas budaya pelanggan

Kompetensi Perusahaan

Keterbukaan dan tranparansi

Implementasi kebijakan

Kebijakan perusahaan

Keyakinan pada manajemen puncak

Pengentahuan dan

Kemampuan SDM

Visi perusahaan

Produk yang ditawarkan

Kedekatan emosional

pelanggan dengan perusahaan

Kemampuan Keuangan

perusahaan

Keyakinan pada karyawan

Penyelesaian keluhan

Tingkat pelayanan

Kinerja jaringan 


\section{2) Skala Pengukuran Variabel}

Alat ukur variabel yang akan digunakan dalam penelitian ini menggunakan pengukuran data interval. Skala interval adalah alat ukur data yang dapat menghasilkan data yang memiliki rentang nilai yang mempunyai makna, walaupun nilai absolutnya kurang bermakna. Skala ini menghasikan measurement yang memungkinkan perhitungan rata-rata, deviasi standard, statistik parameter, korelasi dan sebagainya. Data yang bersifat interval dapat dihasilkan dengan suatu teknik, yaitu bipolar adjective.

Skala ini merupakan penyempurnaan dari semantic scale dengan harapan agar respon yang dihasilkan dapat merupakan intervally scalled data. Caranya dengan memberikan hanya dua kategori ekstrim (Ferdinand, 2006: 147).

\section{3) Structural Equation Modelling (SEM)}

Untuk menguji model dan hipotesis digunakan analisis SEM. Dalam pengujian menggunakan SEM, terdapat tujuh langkah yang ditempuh, yaitu (Ferdinand, 2006: 39)

a. Pengembangan Model Teoritis

Pengembangan model SEM adalah pencarian atau pengembangan sebuah model yang mempunyai justifikasi teoritis yang kuat. Hal yang harus dilakukan adalah melakukan serangkaian eksplorasi ilmiah melaui telaah pustaka yang intens guna mendapatkan justifikasi atau model teoritis yang dikembangkannya. Tanpa dasar teoritis yang kutat, SEM tidak dapat digunakan. Hal ini disebabkan karena SEM tidak digunakan untuk menghasilkan sebuah model, tetapi digunakan untuk mengkonfirmasi model teoritis tersebut, melalui data empirik.

b. Pengembangan Diagram alur (Path diagram)

Sebuah model berbasis teori akan digambarkan pada sebuah path diagram untuk diestimasi dengan mengunakan program AMOS 16.0. Path diagram model penelitian sebagaimana dalam gambar berikut ini :

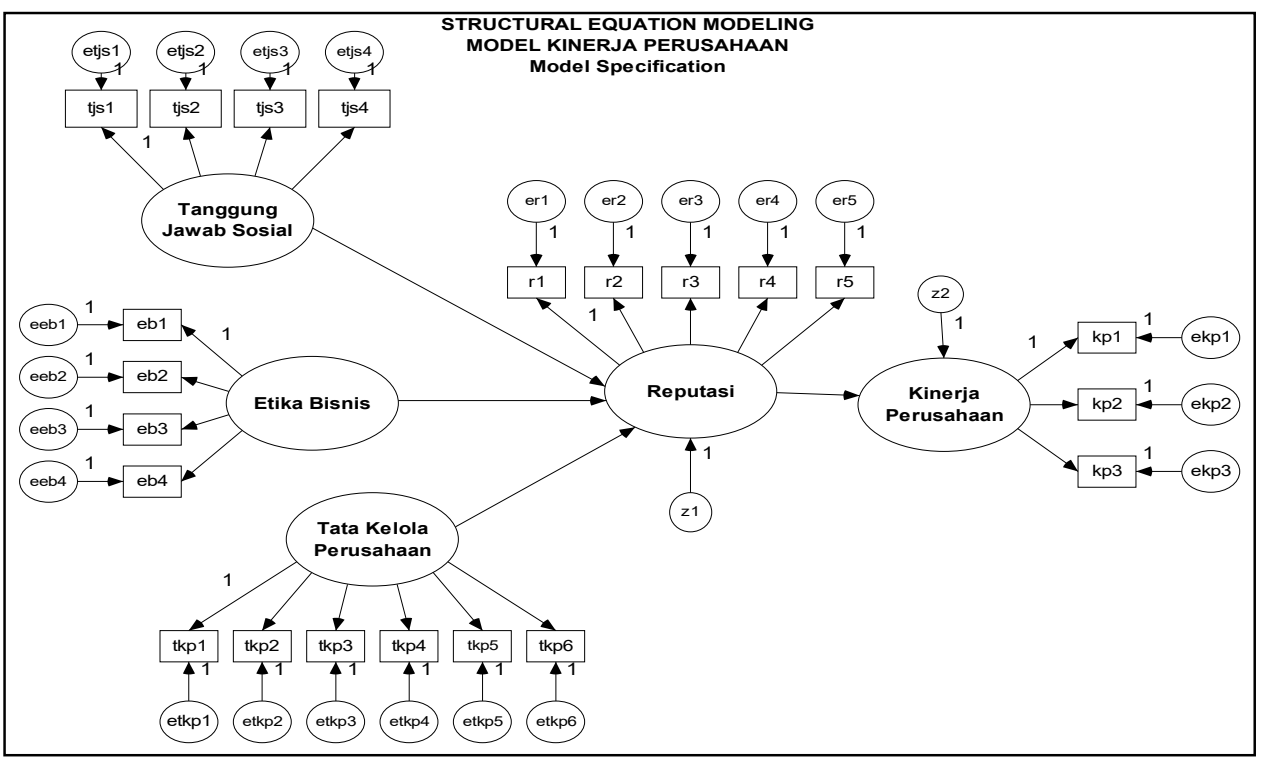

Gambar 1. Path Diagram Model Peneliti

Sumber: dikembangkan untuk penelitian

Keterangan:

tjs1 $=$ Kode Etis

tjs2 $=$ Kesejahteraan Ekonomi

tjs3 = Kontribusi

tjs4 = Pengalaman peserta

eb1 = Mutu Produk eb2 = Uji Coba Produk

eb3 = Penghormatan Martabat

Manusia

eb4 = Integritas Budaya

Pelanggan

tkp1 = Kompentensi Perusahaan 


\begin{tabular}{|c|c|}
\hline tranpa & ansi \\
\hline tkp3 & $=$ Implementasi Kebijakan \\
\hline tkp4 & $=$ Kebijakan perusahaan \\
\hline tkp5 & $=$ Keyakinan pada \\
\hline manaj & men puncak \\
\hline tkp6 & $=\quad$ Pengetahuan \\
\hline Kema & npuan perusahaan \\
\hline r1 & $=$ Visi Perusahaan \\
\hline $\mathrm{r} 2$ & $=$ Produk yang ditawarkan \\
\hline r3 & $=$ Kedekatan emosional \\
\hline pelang & gan dan perusahaan \\
\hline & $\begin{array}{l}=\text { Kemampuan Keuangan } \\
\text { haan }\end{array}$ \\
\hline r5 & $=$ Keyakinan pada karyawan \\
\hline kp1 & $=$ Penyelesaian keluhan \\
\hline kp2 & $=$ Tingkat pelayanan \\
\hline kp3 & $=$ Kinerja jaringan \\
\hline e & $\begin{array}{l}=\text { error disturbance atas } \\
\text { kesalahan pengganggu tiap } \\
\text { indikator ke-i }\end{array}$ \\
\hline $\begin{array}{ll}\lambda \mathrm{i} \\
\mathrm{ke}-\mathrm{i}\end{array}$ & $=$ Koefisien jalur indikator \\
\hline$\gamma \mathrm{i}$ & $\begin{array}{l}=\text { Koefisien jalur variabel ke- } \\
\mathrm{i}\end{array}$ \\
\hline & $=$ Besarnya pengaruh dari \\
\hline
\end{tabular}

\section{4) Uji Hipotesis}

Pengujian
merupakan
pembuktian statistik atas

semua yang telah dihipotesiskan dalam penelitian ini berdasarkan telaah pustaka. Pengujian hipotesis ini didasarkan pada hasil pengolahan data dalam penelitian dengan menggunakan analisis SEM. Secara general, pengujian hipotesis ini dilakukan dengan menganalisis critical ratio (C.R) dan nilai probabilitas ( P ) sebagai hasil dari pengolahan data yang dibandingkan dengan batasan statistik yang dipersyaratkan. Nilai critical ratio yang dipersyaratkan. Nilai critical ratio yang dipersyaratkan diatas 2.00 dan nilai probabilitas dibawah 0.05 . Jika hasildari pengolahan data memenuhi data persyaratan tersebut makahipotesis dalam penelitian yang diajukan dinyatakan dapat diterima.

\section{Hasil Pembahasan}

Jumlah responden dalam penelitian sebanyak 140 responden Pelanggan Korporasi PT. Telkom Indonesia Cab. Kebumen. Dari hasil pengumpulan kuesioner diketahui karakteristik responden berdasarkan, jenis Usaha responden di Korporasi PT. Telkom Indonesia Cab. Kebumen dapat dilihat pada tabel 2 berikut ini:

Tabel 2. Karakteristik responden berdasarkan Jenis Usaha Pelanggan Korporasi PT. Telkom Indonesia Cab. Kebumen Pebruari 2011.

\begin{tabular}{clll}
\hline No. & Jenis Usaha & Jumlah & Persentase \\
\hline 1 & Perhotelan & 4 & $2.86 \%$ \\
2 & Kantor Notaris & 6 & $4.29 \%$ \\
3 & Bank dan Lembaga Keuangan Lainya & 15 & $10.71 \%$ \\
4 & Koperasi & 13 & $9.29 \%$ \\
5 & Warung Internet (warnet) & 12 & $8.57 \%$ \\
6 & Dealer Motor dan Mobil & 11 & $7.86 \%$ \\
7 & Toko Komputer,Toko bahan kelontong, Apotik, & 27 & $19.29 \%$ \\
8 & percetakan & 15 & $10.71 \%$ \\
9 & Kantor Pemerintahan & 10 & $7.14 \%$ \\
10 & Lembaga Pendidikan dan Pelatihan & 7 & $5.00 \%$ \\
11 & Distributor,Jasa perjalanan & 20 & $14.29 \%$ \\
\hline
\end{tabular}


Dari Tabel di atas dapat diketahui bahwa dari 140 responden, mayoritas responden adalah toko komputer, toko bahan kelontong, apotik dan percetakan yaitu sebanyak 27 pelanggan atau 19,29\%, sedangkan yang paling sedikit adalah perhotelan sebesar 4 pelanggan atau 2,86\%.

\section{1) Analisis Statistik Deskriptif}

Analisis ini dimaksudkan untuk mengetahui distribusi frekuensi jawaban responden dari daftar pertanyaan yang disebarkan dan berisikan variabel tanggung jawab sosial, etika bisnis, tata kelola perusahaan, reputasi dan kinerja perusahaan. Penilaian pada hasil penelitian menurut distribusi jawaban responden pada masingmasing variabel didasarkan pada katagori sebagaimana dalam tabel 4.2 berikut ini :

Tabel 3. Standar katagori penilaian hasil distribusi jawaban responden

\begin{tabular}{cc}
\hline Skala Interval & Kategori \\
\hline $1.00-2,80$ & Rendah \\
$>2,80-4,60$ & Kurang \\
$>4,60-6,40$ & Cukup \\
$>6,40-8,20$ & Tinggi \\
$>8,20-10,00$ & Sangat Tinggi \\
\hline
\end{tabular}

Deskripsi jawaban responden pada variabel tanggung jawab sosial dilihat pada tabel 4.3.

Tabel 4. Deskripsi jawaban pada variabel tanggung jawab sosial

\begin{tabular}{llllllllllll}
\hline Pernyataan & \multicolumn{1}{l}{ Skor Jawaban } & \multicolumn{1}{l}{ Sallata } \\
\cline { 2 - 12 } & 1 & 2 & 3 & 4 & 5 & 6 & 7 & 8 & 9 & 10 & Rata-Rata \\
\hline 1 & 0 & 0 & 0 & 6 & 19 & 15 & 22 & 24 & 31 & 23 & 7,60 \\
2 & 0 & 0 & 4 & 4 & 18 & 20 & 17 & 23 & 31 & 23 & 7,50 \\
3 & 0 & 0 & 1 & 7 & 15 & 14 & 31 & 31 & 20 & 21 & 7,46 \\
4 & 0 & 0 & 1 & 7 & 22 & 21 & 17 & 73 & 17 & 12 & 7,16 \\
\hline Jumlah & 0 & 0 & 6 & 24 & 74 & 70 & 87 & 121 & 99 & 79 & 7,43 \\
\hline Persentase & 0 & 0 & 1,0 & 4,2 & 13,2 & 12,50 & 15,54 & 21,61 & 17,68 & 14,1 & 100 \\
& & & 7 & 9 & 1 & & & & & 1 & \\
\hline
\end{tabular}

Dari 140 responden yang memberikan jawaban pada variabel tanggung jawab sosial untuk masing-masing indikator menunjukan angka nilai yang tinggi yaitu rata-rata 7,43 dari total indikator. Hal ini menunjukan bahwa sebagian responden penelitian ini dalam hal tanggung jawab sosial adalah tinggi. Dari hasil distribusi jawaban responden untuk variabel tanggung jawab sosial nilai rata-rata yang paling tinggi juga masuk dalam kategori tinggi yaitu pada indikator kode etis sebesar 7,60, hal ini sesuai dengan jawaban hasil jawaban pertanyaan terbuka sebagian besar responden menyatakan pelaksanaan CSR yang dilakukan PT Telkom cabang Kebumen sudah bagus hanya perlu ditingkatkan lagi seperti masalah fasilitas hot spot yang sangat membantu masyarakat dalam berinteraksi melalui internet secara tidak langsung akan menambah wawasan masarakat walaupun ada sebagian kecil responden menyatakan program CSR yang dilakukan tidak ada kaitanya dengan bisnis mereka. Deskripsi jawaban responden pada variabel etika bisnis dilihat pada tabel 5.: 
Tabel 5.Deskripsi jawaban pada variabel etika bisnis

\begin{tabular}{|c|c|c|c|c|c|c|c|c|c|c|c|}
\hline \multirow[t]{2}{*}{ Pernyataan } & \multicolumn{11}{|c|}{ Skor Jawaban } \\
\hline & 1 & 2 & 3 & 4 & 5 & 6 & 7 & 8 & 9 & 10 & $\begin{array}{l}\text { Rata- } \\
\text { rata }\end{array}$ \\
\hline 1 & 0 & 0 & 1 & 9 & 21 & 10 & 29 & 23 & 33 & 14 & 7,34 \\
\hline 2 & 0 & 0 & 0 & 6 & 16 & 22 & 29 & 22 & 31 & 14 & 7,39 \\
\hline 3 & 0 & 0 & 1 & 10 & 9 & 28 & 18 & 32 & 21 & 21 & 7,41 \\
\hline 4 & 0 & 0 & 1 & 5 & 16 & 22 & 20 & 31 & 27 & 18 & 7,47 \\
\hline Jumlah & 0 & 0 & 3 & 30 & 62 & 82 & 96 & 108 & 112 & 67 & 7,40 \\
\hline Persentase & 0 & 0 & 0,54 & 5,36 & 11,07 & 14,64 & 17,14 & 19,29 & 20,00 & 11,96 & 100 \\
\hline
\end{tabular}

Dari 140 responden yang memberikan jawaban pada variabel etika bisnis untuk masing-masing indikator menunjukan angka nilai yang tinggi yaitu rata-rata 7,40 dari total indikator. Hal ini menunjukan bahwa sebagian responden penelitian ini memiliki persepsi terhadap etika bisnis PT. Telkom Cabang Kebumen adalah tinggi. Dari hasil distribusi jawaban responden untuk variabel etika bisnis nilai rata-rata yang paling tinggi juga masuk dalam kategori tinggi yaitu pada indikator integritas budaya pelanggan sebesar 7,47. hal ini sesuai dengan jawaban hasil jawaban pertanyaan terbuka sebagian besar responden menyatakan bahwa etika bisnis yang dilakukan PT Telkom sudah bagus hanya perlu ditingkatkan lagi dalam pelayanan utamanya kualitas produk masih perlu ditingkatkan agar kepuasan pelanggan dapat terjamin, dalam mengiklankan produknya masih sering mencela dan menyindir pihak pesaing untuk itu Telkom harus selalu menjaga dan meningkatkan kualitas beretika dalam bisnisnya.

Deskripsi jawaban responden pada variabel tata kelola perusahaan dilihat pada tabel 6. :

Tabel 6. Deskripsi jawaban pada variabel tata kelola perusahaan

\begin{tabular}{clllllllllll}
\hline Pernyataan & \multicolumn{1}{l}{ Skor Jawaban } & \multicolumn{1}{l}{ Rata-Rata } \\
\cline { 2 - 12 } & 1 & 2 & 3 & 4 & 5 & 6 & 7 & 8 & 9 & 10 & Rat \\
\hline 1 & 0 & 0 & 3 & 6 & 15 & 19 & 16 & 40 & 27 & 14 & 7,41 \\
2 & 0 & 0 & 1 & 8 & 15 & 17 & 22 & 34 & 28 & 15 & 7,43 \\
3 & 0 & 0 & 0 & 7 & 14 & 23 & 32 & 30 & 20 & 14 & 7,29 \\
4 & 0 & 0 & 1 & 6 & 20 & 13 & 22 & 36 & 26 & 16 & 7,44 \\
5 & 0 & 0 & 1 & 6 & 16 & 14 & 25 & 35 & 26 & 17 & 7,50 \\
6 & 0 & 0 & 1 & 6 & 14 & 23 & 18 & 35 & 27 & 16 & 7,46 \\
\hline Jumlah & 0 & 0 & 7 & 39 & 94 & 109 & 135 & 210 & 154 & 92 & 7,42 \\
\hline Persentase & 0 & 0 & 0,83 & 4,64 & 11,19 & 12,98 & 16,07 & 25,00 & 18,33 & 10,95 & 100 \\
\hline
\end{tabular}

Dari 140 responden yang memberikan jawaban pada variabel tata kelola perusahaan untuk masing-masing indikator menunjukan angka nilai yang tinggi yaitu rata-rata 7,42 dari total indikator. Hal ini menunjukan bahwa sebagian responden penelitian ini memiliki persepsi terhadap tata kelola perusahaan PT. Telkom Cabang Kebumen adalah tinggi. Dari hasil distribusi jawaban responden untuk variabel tata kelola perusahaan nilai rata-rata yang paling tinggi juga masuk dalam kategori tinggi yaitu pada indikator keyakinan pada manajemen puncak sebesar 7,50. hal ini sesuai dengan jawaban hasil jawaban pertanyaan terbuka sebagian besar responden menyatakan bahwa tata kelola perusahaan yang dilakukan PT Telkom telah menerapkan standar manajemen global dan selalu update terhadap segala perkembangan teknologi informasi, kredibilitas perlu ditingkatkan lagi, petugas dan pegawai sudah cukup mempunyai pengetahuan dan kemampuan yang menunjang terutama dalam melayani kebutuhan pelanggannya. Dengan demikian berarti bahwa faktor-faktor yang mendukung 
adanya tata kelola perusahaan PT. Telkom Indonesia Cabang Kebumen bisa ditingkatkan lagi agar tata kelola yang dilaksanakan akan semakin tinggi.Deskripsi jawaban responden pada variabel reputasi dilihat pada tabel 4.6.

Tabel 7. Deskripsi jawaban pada variabel reputasi

\begin{tabular}{cccccccccccc}
\hline Pernyataan & \multicolumn{10}{c}{ Skor Jawaban } \\
\cline { 2 - 13 } & 1 & 2 & 3 & 4 & 5 & 6 & 7 & 8 & 9 & 10 & Rata-rata \\
\hline 1 & 0 & 0 & 0 & 5 & 16 & 15 & 22 & 29 & 37 & 16 & 7,64 \\
2 & 0 & 0 & 0 & 6 & 15 & 19 & 19 & 29 & 30 & 22 & 7.63 \\
3 & 0 & 0 & 0 & 4 & 19 & 18 & 22 & 28 & 32 & 17 & 7,54 \\
4 & 0 & 0 & 0 & 6 & 21 & 15 & 22 & 33 & 28 & 15 & 7,42 \\
5 & 0 & 0 & 1 & 8 & 19 & 14 & 26 & 30 & 27 & 15 & 7,35 \\
\hline Jumlah & 0 & 0 & 1 & 27 & 85 & 90 & 103 & 154 & 154 & 86 & 7.51 \\
\hline Persentase & 0 & 0 & 0,1 & 3,86 & 12,14 & 12,8 & 14,71 & 22,00 & 22,00 & 12,29 & 100 \\
& & & 4 & & & 6 & & & & & \\
\hline
\end{tabular}

Dari 140 responden yang memberikan jawaban pada variabel reputasi untuk masing-masing indikator menunjukan angka nilai yang tinggi yaitu rata-rata 7,51 dari total indikator. Hal ini menunjukan bahwa sebagian responden penelitian ini memiliki persepsi terhadap reputasi PT. Telkom Cabang Kebumen adalah tinggi. Dari hasil distribusi jawaban responden untuk variabel reputasi nilai rata-rata yang paling tinggi juga masuk dalam kategori tinggi yaitu pada indikator visi perusahaan sebesar 7,64. hal ini sesuai dengan jawaban hasil jawaban pertanyaan terbuka sebagian besar responden menyatakan bahwa reputasi PT Telkom sudah baik terbantu oleh produk-produk baru yang inovatif dan bersaing, banyak SDM berkemapuan tinggi tapi lambat dalam menanggapi keluhan pelanggan terutama produk speedy. Dengan demikian berarti faktor-faktor yang mendukung adanya reputasi PT. Telkom Indonesia Cabang Kebumen bisa ditingkatkan lagi agar reputasinya akan semakin tinggi. Deskripsi jawaban responden pada variabel kinerja perusahaan dilihat pada tabel 8. :

Tabel 8. Deskripsi jawaban pada variabel kinerja perusahaan

\begin{tabular}{|c|c|c|c|c|c|c|c|c|c|c|c|}
\hline \multirow[t]{2}{*}{ Pernyataan } & \multicolumn{11}{|c|}{ Skor Jawaban } \\
\hline & 1 & 2 & 3 & 4 & 5 & 6 & 7 & 8 & 9 & 10 & Rata-rata \\
\hline 1 & 0 & 0 & 3 & 3 & 17 & 29 & 32 & 32 & 13 & 11 & 7,05 \\
\hline 2 & 0 & 0 & 1 & 9 & 11 & 18 & 32 & 36 & 21 & 12 & 7,31 \\
\hline 3 & 0 & 0 & 1 & 8 & 16 & 23 & 20 & 30 & 30 & 12 & 7,31 \\
\hline Jumlah & 0 & 0 & 5 & 20 & 44 & 70 & 84 & 98 & 64 & 35 & 7,22 \\
\hline Persentase & 0 & 0 & 1,19 & 4,76 & 10,48 & 16,67 & 20,00 & 23,33 & 15,24 & 8,33 & 100 \\
\hline
\end{tabular}

Dari 140 responden yang memberikan jawaban pada variabel kinerja perusahaan untuk masing-masing indikator menunjukan angka nilai yang tinggi yaitu rata-rata 7,22 dari total indikator. Hal ini menunjukan bahwa sebagian responden penelitian ini memiliki persepsi terhadap kinerja perusahaan PT. Telkom Cabang Kebumen adalah tinggi. Dari hasil distribusi jawaban responden untuk variabel kinerja perusahaan nilai rata-rata yang paling tinggi juga masuk dalam kategori tinggi yaitu pada indikator tingkat pelayanan dan kinerja jaringan sebesar 7,31 hal ini sesuai dengan jawaban hasil jawaban pertanyaan terbuka sebagian besar responden menyatakan bahwa kinerja PT Telkom sudah baik, namun masih perlu peningkatkan lagi, misalnya secara periodik jaringan perlu di kontrol sehingga suara menjadi bersih, spidy yang digunakan juga kecepatannya sesuai dengan speed yang telah ditetapkan Telkom. Dengan demikian berarti bahwa faktor-faktor yang mendukung kinerja perusahaan PT. Telkom Indonesia Cabang Kebumen bisa ditingkatkan lagi agar kinerjanya akan semakin tinggi. 
2) Structural Equation Modeling (SEM)

Setelah model dianalisis melalui confirmatory factor analysis dan dapat dilihat bahwa masing-masing indikator dapat didifinisikan kontruk laten, maka sebuah full model SEM dapat dianalisis. Hasil pengolahan AMOS 16.0 adalah sebagai berikut :

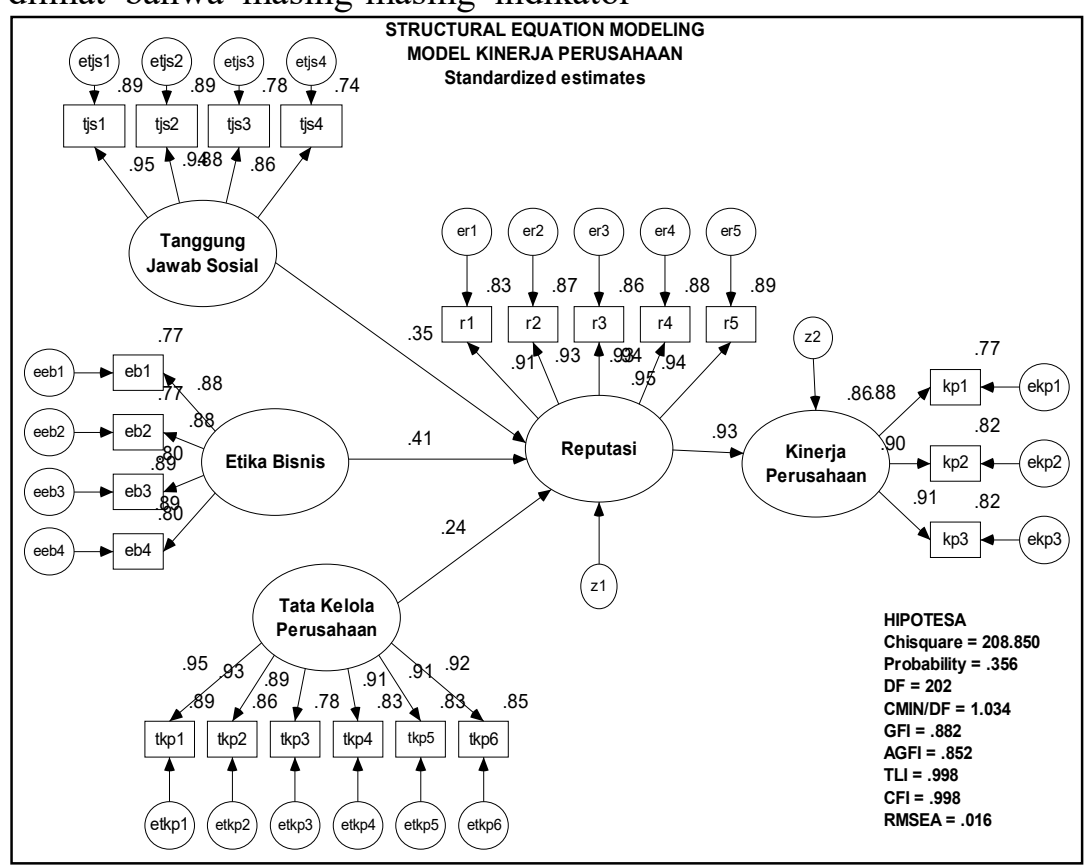

Gambar2. Structural Equation Modeling Faktor-Faktor yang mempengaruhi Kinerja Perusahaan.

\section{Kesimpulan}

Berdasarkan hasil analisis yang dilakukan, maka kesimpulan yang dapat ditarik dari penelitian ini adalah :

1) Tanggung jawab sosial, berpengaruh terhadap reputasi. Artinya semakin tanggung jawab sosial semakin baik pula reputasi PT. Telkom Indonesia Cabang Kebumen.

2) Etika Bisnis, berpengaruh terhadap reputasi. Artinya semakin baik etika bisnis semakin tinggi pula reputasi PT. Telkom Indonesia Cabang Kebumen.

3) Tata kelola perusahaan, berpengaruh terhadap reputasi. Artinya semakin tinggi tata kelola perusahaan semakin baik pula reputasi PT. Telkom Indonesia Cabang Kebumen.

4) Reputasi berpengaruh terhadap kinerja perusahaan. Artinya semakin baik reputasi semakin baik pula kinerja perusahaan PT. Telkom Indonesia Cabang Kebumen.

\section{Implikasi Manajerial.}

Hasil penelitian ini menunjukkan bahwa di PT. Telkom Indonesia Cabang Kebumen, reputasi perusahaan mempunyai pengaruh dominan terhadap kinerja perusahaan. Disisi lain tata kelola perusahaan mempunyai pengaruh dominan terhadap reputasi, dengan demikian PT. Telkom Cabang Kebumen perlu lebih meningkatkan tata kelola perusahaan yang lebih baik dengan cara penerapan kebijaksanaan dan pratek good governance dengan standar nasional yang telah ditetapkan sehingga reputasi perusahaan meningkat dan dampaknya akan meningkatkan kinerja perusahaan. 


\section{Implikasi Untuk Penelitian Mendatang}

Berdasarkan hasil penelitian dan keterbatasan yang ada pada penelitian ini segi model struktural yang digunakan, model ini sudah baik dilihat dari uji cofirmatory dan goodness-of-fitnya. akan tetapi sebaiknya untuk topik kinerja perusahaan perlu menggali lebih dalam variabel maupun indikator-indikator yang digunakan. Penelitian mendatang juga dapat mempertimbangkan obyek penelitian yang akan digunakan bukan saja pada perusahaan jasa telekomunikasi namun dapat dikembangkan pada organisasi bisnis yang lainnya.

\section{Daftar Pustaka}

Agenda. (2001). Promoting a European Framework for Corporate Social Responsibility: Group discussion on the links between social responsibility and sustainable development. Agenda: Social Responsibility in Scotland .www.agenda-scotland.org.

Aguilera, R.V., Rupp, D.C., Williams, C.A. and Ganapathi, J. (2007), "Putting the $S$ back in CSR: a multi-level theory of social change in organizations", Academy of Management Review, Vol. 32 No. 3, pp. 83663.

Carney, Michael, and Gedajlovic.2001. “ Corporate Governance and Firm Capabilities: A Comparison of Managerial, Alliance, and Personal Capitalisms", Asia Pasific Jaurnal of Management, Vol. 18 No.3 pp. 335.

Chung, Cheng Hsu, Ming Jian Shen, Ming Chia Chen and Chin Fang Choa. 2006. " A Study on The Relationship Between Corporate Governance Mechanism and Management Effectivesss', The Business Review, Vol. 6 No. 1 pp. 208-217.

Dolphin, Ricard R. 2004. “ Corporate
Reputation- Value Creating Strategy", Corporate Governance Review, Vol. 4 No. 3 pp.77-92.

Dowling, G.R. 2001. " Creating Corporate Reputation", Oxford University Press, Oxford.

Dowling, G.R, 2006. How Good Corporate Reputation Create Corporate Value", Corporate Reputation Review, Vol. 9 No.2 pp. 134-143.

Ernawan, Erni R., 2007. Business Ethics, Penerbit Alfabeta:Bandung Indonesia.

Ferdinand, A. T, 2006, SEM Dalam Penelitian Manajemen, Badan Penerbit Universitas Diponegoro Semarang, Indonesia

Fombrun, C.J. 2005. " Building Corporate Reputation Through CSR Initiatives: Evolving Standards", Corporate Reputation Review, Vol. 33, No.2 pp. 233-258.

Fombrun, C.J, Shanley, M. 1996. “ What's in a name? Reputation Building and Corporate Strategy", Academy of Management Journal. Vol. 33 No.2, pp. 233-58.

Fombrun, C.J. 2006. " Corporate Governance", Corporate Reputation Review, Vol.8 No.4 pp.267.

Fombrun, C.J and Foss, Christopher. 2004. "Business Ethics: Corporate Responses to Scandal", Corporate Reputation Review,Vol. 7, No. 3, pp. 284288.

Friedman, M., 1970, "The Social Responsibility of Business is to Increase its Profits", New York Times Magazines, September.

Gabriel, Juan, Navarro, Cegarra and Martínez, Aurora. 2009. “ Linking corporate social responsibility with admiration through organizational outcomes", Social Responsibility Journal, Vol. 5 No.4 pp. 499-511. 
Julian, Rick, Larry Rieger. 2003. "The Missing Link in Corporate Governance Risk Manager's Role in Corporate Governance", No. 4, Vol. 50; pp. 32.

Kerap, Sony. 2002. Etika Lingkungan, Penerbit Buku Kompas: Jakarta

Lewis, Steward. 2001. "Measuring Corporate Reputation", Corporate Communications An International Journal, Vol.6 No.1 pp.31-35.

Maignan, I.M. (2001), "Consumers' perceptions of corporate social responsibilities: a cross-cultural comparison', Journal of Business Ethics, Vol. 30 No. 1, pp. 57-72.

Nguyen, N., Leblance, G. 2001. "Corporte Image and Corporate Reputation in Customers" Rentension Decision in Services", Journal of Retailing and Cunsumer Services, Vol.8 No.4 pp.227-236.

Oetzel, Jennifer, Gets, Kethleen A., and Ladeck, Stephen. 2007. “ The Role of Multinational Enterprises in Responding to Violent Conflict : A Conceptual Model and Framework for Research", American Business Law Journal, Vol. 44 No. 2 pp. 331.

Puente, E., and Sabate J.M .2003. “ Empirical Analysis of the Relationship Beten Corporate Reputation and Financial Performance : A survey of the Literature ", Corporate Reputation Review, Vol. 2 No. 3 pp. 105-112.

Puente, Esther D.Q, Sabate, Juan Manuel D.L.F and Gracia, Juan B.D. 2007. "Corporate Social Performance and Corporate Reputation: Two Interwoven Perspectives", Corporate Reputation Review, Vol 10.
No.1 pp. 60-72.

Qu, Riliang.2007. “ Effect of Government Regulations, Market Orientation, and Ownership Structure and Corporate Social Responsibility in China: An Empirical Study", International Journal of Management, Vol. 24 No. 3 pp.582

Sangarimbun, Masri dan Effendi, Sofian. 1987. Metode Penelitian Survai, Jakarta: LP3ES.

Sutojo, Siswanto \& E. John Aldridge.2005. “ Good Corporate Governance" , Jakarta, Indonesia, Damar Mulia Pustaka.

Suta, I Putu Gede Ary. 2006. Kinerja Pasar Publik di Indonesia (Suatu Analisis Reputasi Pasar), Yayasan SAD Satria Bakti, Jakarta.

Thomas, A. Hemphill.2006. " Corporate Internal Investigations: Balancing Firm Social Reputation With Broad Fiduciary Responsibility in China: an Empirical Study", Internasional Journal of Management. Vol.24 No.3 pp.582. Versi, Anver.2007. " CSR-Fist Prinsiple of Survival", African Business, No.328 pp. 34.

Valasques, M. 2005. Business Ethics, Concept and Cases, Printice Hall : Englewood Cliftts.

Wang, Yonggui,. Kandaampuly, Jay A, Po Lo,Hing and Shi, Guicheng. 2006. The Roles of Brand Equity and Corporate Reputation in CRM : A Chinese Study, Corporate Reputation Review, Vol. 9 No. pp.179-197.

Wartick, S.L. 2002. “ Measuring Corporate Reputation: Definition and Data", Business and Society", Corporate Reputation Review, Vo.41 No.4 pp.371-392. 